\title{
Assessment of Behaviour of Super Capacitor-battery System in Heavy Hybrid Lift Truck Vehicles
}

\author{
Noshin Omar ${ }^{1}$, Joeri Van Mierlo ${ }^{2}$, Frederik Van Mulders ${ }^{3}$, and Peter Van den Bossche ${ }^{4}$ \\ ${ }^{1}$ Department of Electrical Engineering and Energy Technology,Vrije Universiteit Brussel,noshomar@vub.ac.be \\ ${ }^{2}$ Department of Electrical Engineering and Energy Technology,Vrije Universiteit Brussel, jvmierlo@vub.ac.be \\ ${ }^{3}$ Department of Industrial Engineering, Erasmus Hogeschool Brussel, frederik.van.mulders@vub.ac.be \\ ${ }^{4}$ Department of Industrial Engineering, Erasmus Hogeschool Brussel, peter.van.den.bossche@docent.ehb.be
}

\begin{abstract}
This paper represents an alternative energy storage system in the drive line of a hybrid electric vehicle. The effect of the use of an EDLC (Electrical Double Layer Capacitors) as a power buffer to smooth rapid power fluctuations in and out of the batteries of a hybrid electric heavy truck is investigated. In this work a topology is presented where the performances of a battery pack in parallel with supercapacitors are evaluated in terms of stress and extending battery lifespan. According to this association the battery current drawn is reduced and the supercapacitor source supplies the majority of transient current and as a result the battery stress is reduced up to $30 \%$. Other laboratory tests showed a fourfold improvement over stand alone lead acid battery pack under a Dynamic Endurance Test in which the lifetime of the battery is increased with $30 \%$. This work has been carried out on computer simulations. Finally the simulations results are validated on a test bench.
\end{abstract}

\section{Keywords}

battery model, simulations results, electrical double layer capacitors, lead acid, dynamic endurance test

\section{INTRODUCTION}

As the global economy begins to strain under the pressure of rising petroleum prices and environmental concerns have spurred research into the development of various types of Hybrid Electric Vehicles (HEV's). Due to their several on-board power sources, HEV's offer unprecedented possibilities to pursue low energy consumption, higher efficiency, increasing life time of energy sources as well as reducing size and cost [Emadi et al., 2005]. The battery pack (lead acid) in conventional fork lift trucks, is sized for peak power demand. Cycling the battery at high power rates leads to [Bockeris et al., 1981]:

(1) To reduce available capacity. This reduced capacity is caused by the isolation of active material due to the blocking of $\mathrm{PbSO}_{4}$ molecules by sulphate deposition during high rate discharge, which has twice the volume of the $\mathrm{PbO}_{2}$.

$$
\mathrm{Pb}+\mathrm{PBO}_{2}+2 \mathrm{HSO}_{4}^{-}+2 \mathrm{H}^{+} \Rightarrow 2 \mathrm{PbSO}_{4}+2 \mathrm{H}_{2} \mathrm{O}
$$

The number and the position of these molecules depend on the reaction speed which is linked to the discharge current value. These molecules have the properties of bad conductors. So the battery capacitance value is lower than with small cur- rents. The higher the current, the less are the amperes hours (Ah's) furnished by the battery. This effect has been already investigated by Peukert [Bockeris et al., 1981; Kozawa, et al., 2005].

(2) Physical degradation of the battery structure. High discharge currents normally encountered by the battery lead to higher RMS currents, with accompanying higher operating temperatures.

This gives rise to considerably shorter battery lifetime, due to increased grid corrosion, and increased gassing within the battery, leading to separator dry out, and eventual cell failure [Adam et al., 2006].

Degradation of the active mass can be reduced by minimizing the currents in the batteries. Additionally, the temperature of the batteries will be lower and this will reduce corrosion and sulphation. Therefore the lifetime of the batteries should be extended. Another potential benefit of minimizing battery currents is increased reliability of the batteries by reducing the chance of a catastrophic failure through short circuiting or thermal runaway [Adam et al., 2006; Achaibou et al.. 2008; Cooper et al., 2009].

Under such background, a hybrid energy storage system consisting of a battery with high specific energy and supercapacitor with high specific power will be proposed.

In this study, the topology consisting of a battery pack connected directly in parallel to the supercapacitors is 


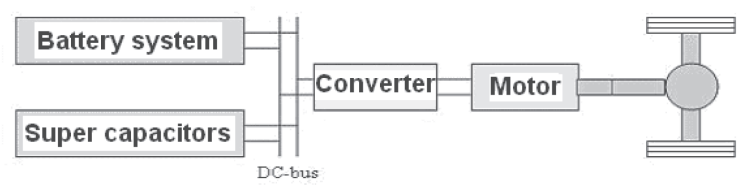

Fig. 1 A parallel connection of batteries to EDLC

investigated (Figure 1). The goal of this association is to reduce battery stress in order to extend the lifespan of the battery pack.

\section{TRUCK DESCRIPTION}

The vehicle system considered in this study is an electric lead-acid powered fork lift truck (CARER R45 NCF). This vehicle is designed to drive with a maximum speed of about $16 \mathrm{~km} / \mathrm{h}$. It can lift max. $4,500 \mathrm{~kg}$. Further, it has two DC-motors; one is used for driving the vehicle $17 \mathrm{~kW}$ and the other one for lifting $15 \mathrm{~kW}$. The mast is hydraulically operated by one or more hydraulic cylinders. The battery pack has a capacity of $960 \mathrm{Ah}$ and the operating voltage is $80 \mathrm{~V}$.

\section{METHODOLOGY}

To model HEV systems is quite a complex task. There are several software environments suitable for analysing such systems. For this task the Matlab ${ }^{\circledR}$ Simulink $^{\circledR}$ software program has been used to model the vehicle system. It is at present a widely spread simulation program both in industry and in academia. Other accessible simulations models are Modelica, Advisor, CRUISE, Vehicle Simulation Program (VSP) [Van Mierlo, 2000], SIMPLEV and EHVSP.

A simulation program based on the "effect cause" also called the "wheel-to engine" has been developed [Van Mierlo, 2000]. The simulation method goes upstream the vehicle components until it reaches the energy source. It can model the current flow in light, mild and heavy off-road vehicles. Starting from a given load profile, it calculates the current requested by the bat- tery pack and from the supercapacitors pack. Figure 2 shows a detail of the lift truck model inside the simulation program.

\section{SIMULATION MODEL}

To evaluate the behavior of supercapacitors connected in parallel to batteries, a simulation model based on the circuit as displayed in Figure 3 is required. The model is enabled to calculate the current contribution of each branch to an imposed load profile. By giving the internal resistances of the battery and the supercapacitor pack, the supercapacitor capacitance and the starting voltage, the model can calculate the respective current distributions to the peak load.

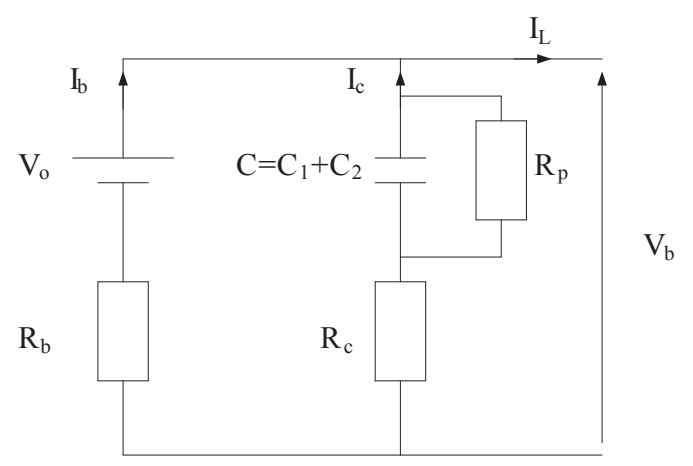

Fig. 3 Parallel setup of supercapacitors and batteries

To use supercapacitors as an energy storage device in vehicles, several cells in series or parallel-series are needed because of their low voltage. The pack model can be simplified by modeling a single cell and choosing the type of cell association to design the pack [Barrade et al., 2003]. The supercapacitor model is made up of an internal resistance $R_{c}$ and a resistance in parallel $R_{P}$ representing resistance the self discharge [Van Mierlo et al., 2003].

The leakage resistance $R_{P}$ can be ignored without much error, the supercapacitor model can simply be presented by a series $\mathrm{RC}$-circuit. The model has further an equivalent capacitance $\mathrm{C}$ that has two compo-

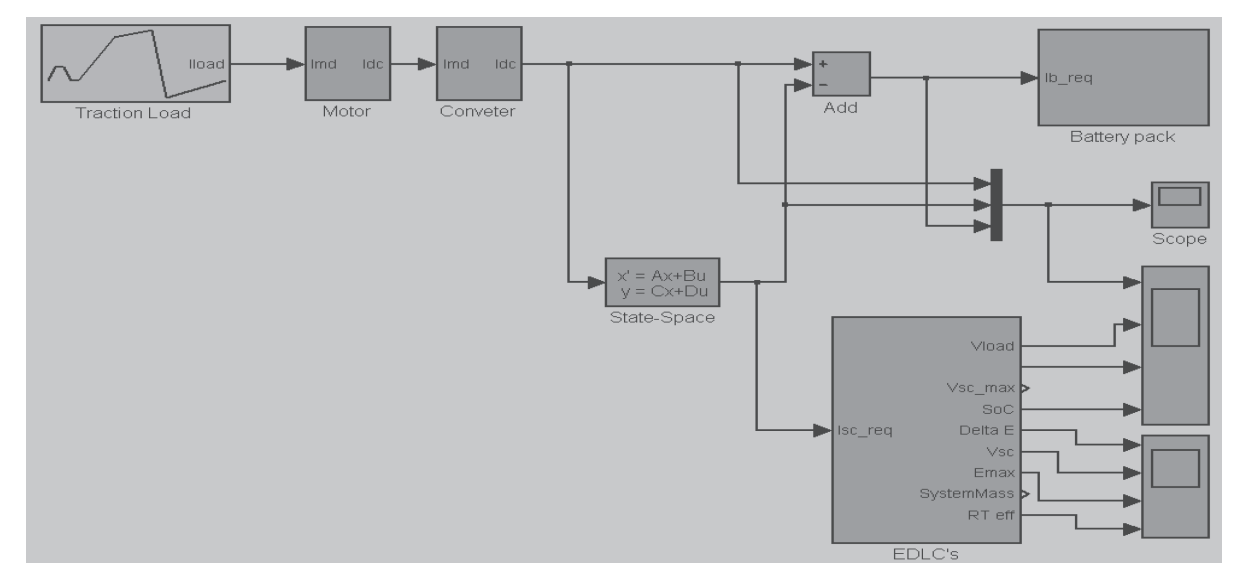

Fig. 2 Simulation model of lift truck according to topology presented in Figure 1 
Tabel 1 Maxwell cell parameters [Maxwell, 2009]

\begin{tabular}{|l|c|c|c|}
\hline Name & Symbol & Value & Unit \\
\hline Cell Number in series & $\mathrm{N}_{\mathrm{R}}{ }^{\mathrm{S}}$ & 30 & - \\
\hline Cell resistance & $\mathrm{ESR}$ & 0.8 & $\mathrm{~m} \Omega$ \\
\hline Initial capacitance & $\mathrm{C}$ & 650 & $\mathrm{~F}$ \\
\hline Rated cell voltage & $\mathrm{V}_{\text {cell }}$ & 2.7 & $\mathrm{~V}$ \\
\hline
\end{tabular}

nents: 1) $\mathrm{C}_{1}$, which changes as function of voltage and has as a role to give the evolution of energy during the times of charge and discharge, and 2) $\mathrm{C}_{2}$, which describes the internal distribution of energy after the charge or discharge.

The battery is modelled by an equivalent electric circuit. It is composed of a voltage source $\mathrm{V}_{\mathrm{o}}$ with an internal resistance $R_{b}$. It is not easy to develop a general model that takes into account all the battery phenomena as physics and chemical because of their relative complexity. The existing models in the literature for lead-acid technology are generally complex to implement, because several parameters have to be determined. The used battery model is represented in Figure 3.

Table 2 Battery parameters

\begin{tabular}{|l|c|c|c|}
\hline Name & Symbol & Value & Unit \\
\hline Capacity & $\mathrm{C}_{\mathrm{b}}$ & 960 & $\mathrm{Ah}$ \\
\hline Voltage & $\mathrm{V}_{\mathrm{b}}$ & 80 & $\mathrm{~V}$ \\
\hline Internal resistance & $\mathrm{R}_{\mathrm{b}}$ & 80 & $\mathrm{~m} \Omega$ \\
\hline
\end{tabular}

\section{SIMULATION RESULTS}

Simulations were performed using a realistic current profile of battery powered lift truck as presented in Figure 4. This figure illustrates the division of current between the battery and supercapacitor in function of the time. The red line represents the required current while the blue and green lines represent the battery and supercapacitor current. It can be seen that

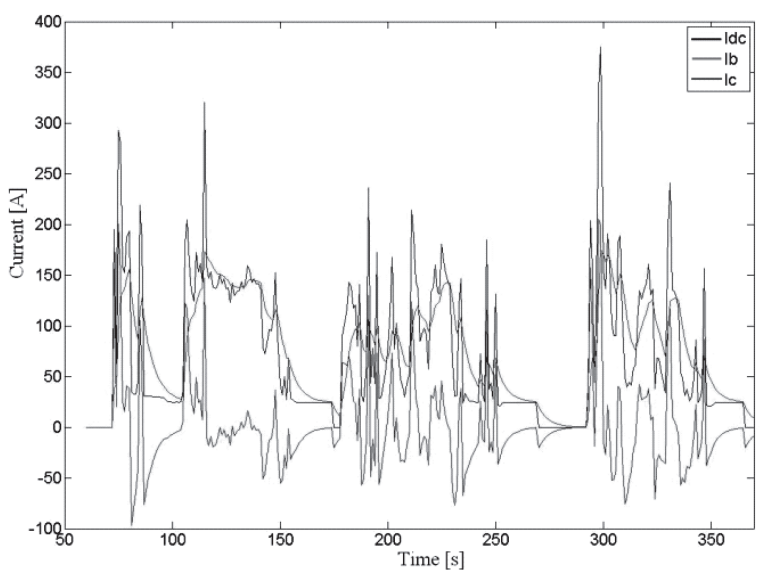

Fig. 4 Current flow versus time the short time constant of the supercapacitor allow to supply most of the energy in transient state while in steady state the batteries current ramps up slowly and the supercapacitor current decreases according to equation 1 .

$I_{b}=I_{L}-\frac{I_{L} \cdot R_{b}}{R_{b}+R_{c}} e^{-t / \tau}$

Where: $\tau=\mathrm{C}\left(\mathrm{R}_{\mathrm{b}}+\mathrm{R}_{\mathrm{c}}\right)$ is the time constant

Further, noticeable in Figure 5, the supercapacitor voltage $\mathrm{V}_{\text {sc }}$ follows the pulse immediately, while after the pulse the supercapacitor voltage begins to rise because the battery is charging the supercapacitor due to the interaction between the supercapacitor and battery packs. The battery current remains in break times positive while the supercapacitor current becomes negative. The battery is effectively charging the supercapacitor during these periods until the supercapacitor voltage is equal to battery voltage.

One can observe that this approach results in a reduction of battery voltage excursions compared with the unassisted battery pack as presented in Figure 5. It is clear that this association allows reducing the battery stress. Consequently, this approach makes it possible to increase the lifetime of the battery and to improve the performances.

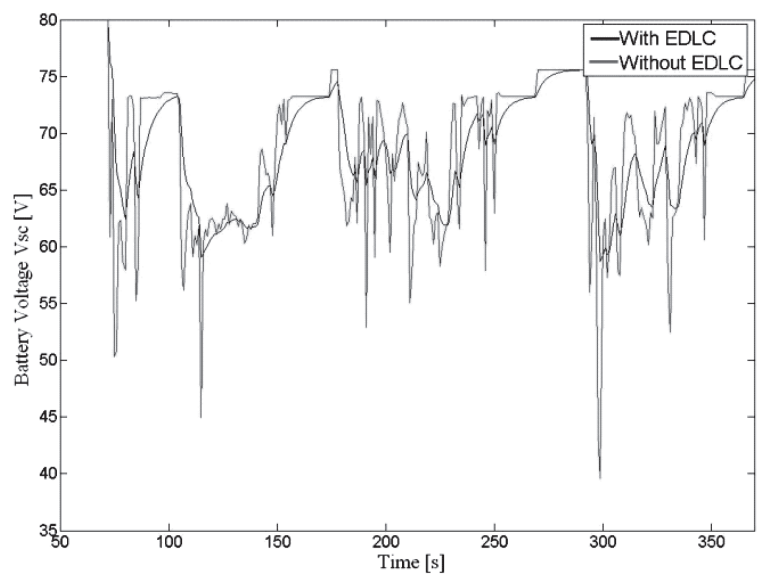

Fig. 5 Battery voltage versus time

\section{TEST BENCH DESCRIPTION}

To evaluate the performances of the battery and the super capacitor system an experimental test platform of hybrid electric vehicles has been used as presented in Figure 6. This platform consists of:

- A battery module of $412 \mathrm{~V}$ VRLA batteries of Enersys $^{\circledR}, 2.5 \mathrm{~m} \Omega$ in series (2);

- Different super capacitors modules (650 F and $2 \times$ 650 F,) of 24 cells Maxwell $^{\circledR}(5)$;

- DC motor LEM200 (6), the motor in the test plat- 


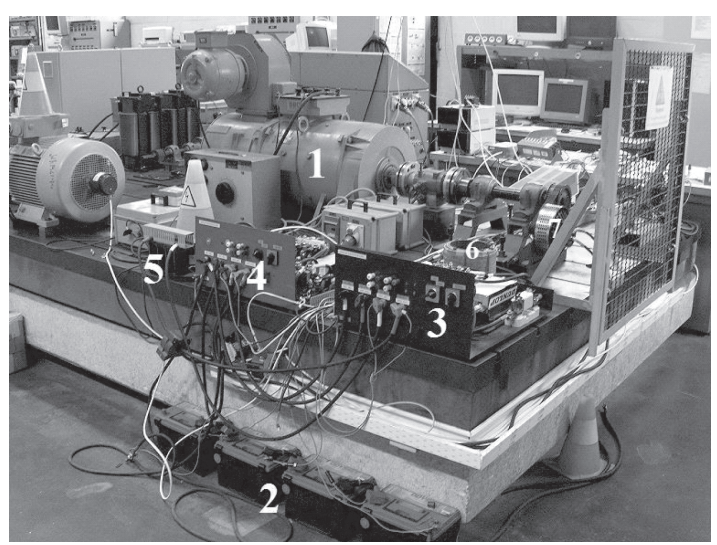

Fig. 6 Test platform of hybrid electric vehicles

form is mechanically coupled to another electrical machine and which will function as the load of the drive train. This machine will be indicated as the "load machine". When the motor of the electric drive train will accelerate, this load machine will have to apply a load torque which corresponds to the torque which would be acting on the motor when used in a vehicle.

- BRUSA $^{\circledR}$ Motor controller (4);

Due to the permissible current through the controller of the motor, limited to $200 \mathrm{~A}$, the load profile (see Figure 4) has been scaled with a factor 2 .

\section{EXPERIMENTAL RESULTS}

A first measurement was performed considering a direct connection of the batteries with a supercapacitor unit to the DC-bus. Both the current coming from the main energy supply system in our case the battery pack $\left(\mathrm{I}_{\mathrm{b}}\right)$, and the current coming from the supercapacitors $\left(I_{c}\right)$ were measured and compared with the simulated results. The comparison of both simulated and measured parameters demonstrates a good correlation when the internal resistance $R_{b}$ is $40 \mathrm{~m} \Omega$ (see Figure 7). The relative error is less than $5 \%$. The mentioned $\mathrm{R}_{\mathrm{b}}$ in the supplier data sheet is often based on statics tests. It doesn't take in account that this parameters is in function of the state of charge and temperature [Van Mierlo et al., 2003].

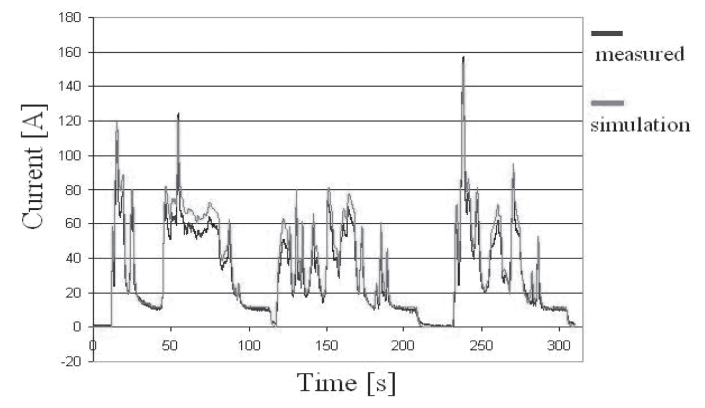

Fig. 7 Measured and simulated current versus time
This value could be used further to analyze the behaviour of the battery pack with supercapacitor unit in a simulation model.

When considering the current coming from the battery pack $\left(\mathrm{I}_{\mathrm{b}}\right)$, one can observe that the battery pack has been relieved with $20 \%$ of peak currents (see Figure 8).

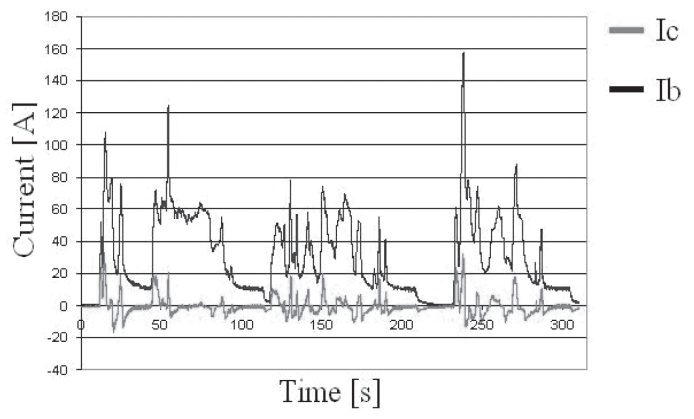

Fig. 8 Measured battery and supercapacitor current versus time for SC capacity $27.3 \mathrm{~F}$

Second test was performed considering 2 strings in parallel. According to equation (2) the capacity of the supercapacitor package will increase to $56.6 \mathrm{~F}$ compared with $27.3 \mathrm{~F}$ in previous association.

$$
C=C_{\text {cell }} \frac{N_{R}^{P}}{N_{R}^{S}}
$$

Due to increasing the capacity, the supercapacitors will be able to provide more energy than before. So the relieving percentage of the battery pack is increased from $20 \%$ to $30 \%$.

Confirmed by simulation and practical tests, this association makes it possible to reduce the battery current. These results to minimize the voltage drop across the internal resistance of the battery.

The RMS current is responsible for the majority of the heating effects in the battery, through ohmic losses $\left(\mathrm{R}_{\mathrm{b}}\right.$. $\mathrm{I}_{\mathrm{b}}{ }^{2}$ ). Minimising this heating (through minimising battery current) will have beneficial effects on the battery lifespan, as gassing and also grid corrosion, are all temperature dependant [Sugimoto et al., 1998].

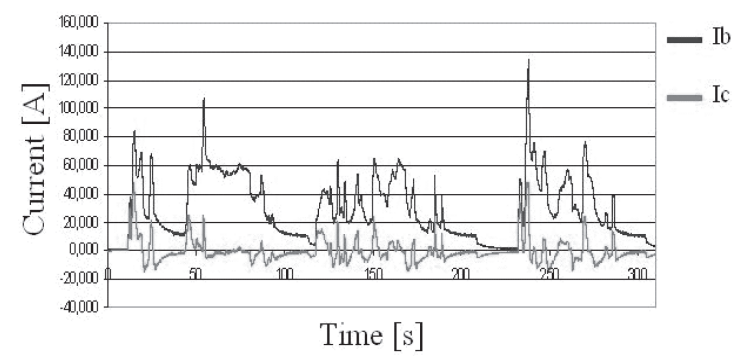

Fig. 9 Measured battery and supercapacitor current versus time for SC capacity $54.6 \mathrm{~F}$ 


\section{LIFE CYCLE ANALYSIS}

We have seen in the previous chapters that the supercapacitors result in reducing the current rates from the batteries, which should extend their lifetime. However, an electric vehicle built by EVermont and tested at the Energy Technology Laboratory of Hydro Quebec found that the supercapacitors did not appreciably extend battery lifetime. However, three of the batteries in the battery pack had catastrophic failures compared to one battery in the supercapacitor assisted pack [Angers, 2005]. Due to the failures more tests would be necessary to determine this. To evaluate this aspect, accelerated life cycle testing was performed using two ENERSYS $12 \mathrm{~V}$ lead-acid batteries with a rated capacity of $57 \mathrm{Ah}\left(\mathrm{C}_{5 \mathrm{~h}}\right)$. Both batteries were subjected to the same current profile: battery only, i.e. case 1 , and $2 \times 6$ cells $600 \mathrm{~F}$ super capacitors in parallel i.e. case 2. The testing was conducted simultaneously using a Digatron BTS600 testing device (see Figure 10).

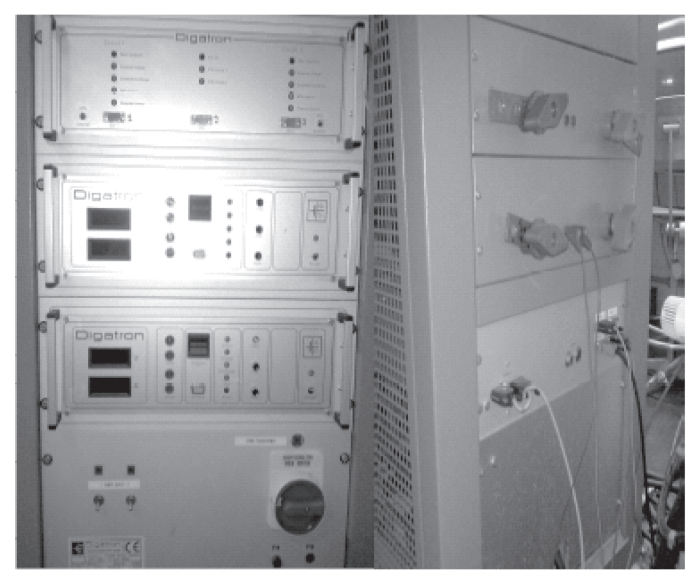

Fig. 10 Testing device digatron

For evaluation, the Dynamic Endurance Test (DET) according to IEC 61982-2 was used as reference as shown in Figure 11. This test is consisting of a microcycle with [Van den Bossche et al., 2007]:

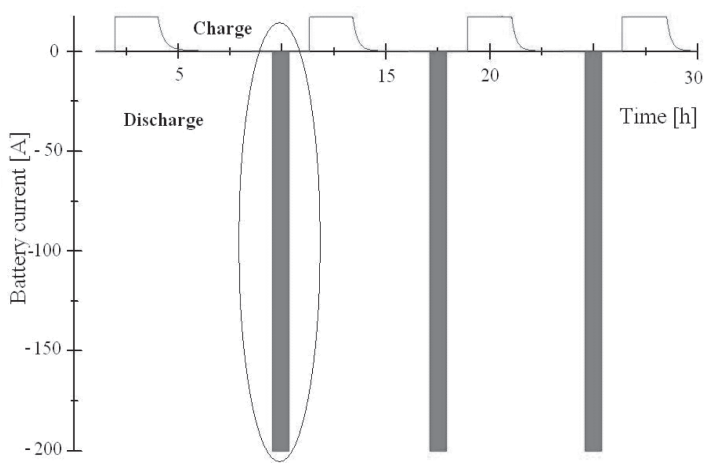

Fig. 11 DET-test

- A high current to simulate acceleration (200 A during $10 \mathrm{~s}$ ) (see Figure 12),

- A low current to simulate constant speed (50 A during $20 \mathrm{~s}$ ),

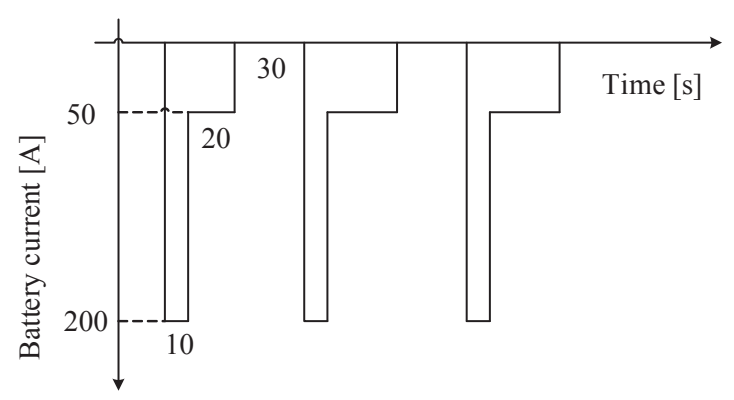

Fig. 12 Micro-cycles during discharge

- No current for pause period (30 s)

Both batteries will be charged and discharged until battery capacity drops to $80 \%$ rated capacity which considers the end of life of battery [Van den Bossche et al., 2007].

The benefit of the supercapacitor to extend the lifetime of the battery has been investigated. In Table 3, one can observe that the battery with a supercapacitor pack in parallel has done 65 cycles compared to 50 cycles without supercapacitors.

Table 3 Results of cycle life analysis

\begin{tabular}{|c|c|}
\hline & \# cycles \\
\hline Without SC & 50 \\
\hline With SC & 65 \\
\hline
\end{tabular}

\section{LIMITATION}

The super capacitor is according to this configuration directly coupled to the DC-bus. An (expensive) DCDC converter and associated management system are not required. However the amount of energy stored in the super capacitors depends on its voltage as expressed in equation (3):

$E=\frac{1}{2} C\left(V_{\max }^{2}-V_{\min }^{2}\right)$

For optimal usage, the super capacitor as a peak power unit, the voltage of the supercapacitor string should not be kept constant. Normally a super capacitor voltage ranges from $50 \%$ to $100 \%$ of its nominal voltage to keep an acceptable efficiency of the energy transfer [Hesam et al., 2008].

\section{CONCLUSION}

In this paper we have proposed a topology where the performances of a battery pack in parallel with supercapacitors are evaluated in terms of stress and extending battery lifespan. According to this association the battery current drawn is reduced and the supercapacitor source supplies the majority of transient current. According to the simulations and experimental results, the battery stress can be reduced up to $30 \%$. Other 
results showed that this approach offers a fourfold improvement over stand alone battery pack in sense of battery voltage excursions. At least accelerated life cycling tests have proved the benefit of this topology in increasing the life time of battery pack with $30 \%$.

\section{Acknowledgements}

This work was financial supported by Institute for the Promotion of Innovation by Science and Technology in Flanders (IWT). The author would like to thank Enersys NV and Emrol NV for providing of both batteries and data.

\section{References}

Achaibou, N., M. Haddadi, and A. Malek, Lead acid batteries simulation including experimental validation, Journal of Power Sources, Vol. 185, No. 2, 1484-1491, 2008.

Adam, W. S., T. Stuart, and A. Cyrus, An ultracapcitor circuit for reducing sulfation in lead acid batteries for mild hybrid electric vehicles, Journal of Power Sources, Vol. 156, No. 2, 755-762, 2006.

Angers, P., Supercapacitors - do they improve battery life?, Electric Vehicle Symposium 21, 2005.

Barrade, P., and A. Rufer, Current capability and power density of supercapacitors: Considerations on energy efficiency, European Power Electronics and Drives, 2003.

Bockris, J. O’M., E. C. Brian, E. Yeager, and R. E. White, Comprehensive Treatise Electrochemistry, Edition 1, Springer, 1981.

Cooper, A., J. Furakawa, L. Lam, and M. Kellaway, The ultrabattery - A new battery design for a new beginning in hybrid electric vehicle energy storage, Journal of Power Sources, Vol. 188, No. 2, 642649, 2009.

Emadi, A., K. Rajashekara, S. S. Williamson, and S. M. Lukic, Topological overview of hybrid electric and fuel cell vehicular power system architectures and configurations, IEEE Transactions on Vehicular Technology, Vol. 54, No. 3, 763-770, 2005.

Hajimiri, M. H., and F. R. Salmasi, A predictive and battery protective control strategy for series HEV, Journal of Asian Electric Vehicles, Vol. 6, No. 2, 1159-1165, 2008.

Kozawa, A., S. Minami, Y. Suzuki, S. Iwata, S. Ikeda, H. Ikeda, J. C. Nandi, and R. J. Brodd, Understanding the beneficial action of organic activators for the negative electrode of lead-acid batteries, Journal of Asian Electric Vehicles, Vol. 3, No. 1, 665 668, 2005.

Sugimoto, S., I. Kouda, and Y. Murai, Energy storage system utilizing large capacity electric double layer capacitors for peak-cut of power demand,
The Transactions of The Institute of Electrical Engineers of Japan, Vol. 118-D, No. 12, 1377-1385, 1998.

Van den Bossche, P., J. Van Mierlo, C. Yonghua, and T. Jean-Marc, Evolution of international standardization of electrically propelled vehicles, EET-2007 European Ele-Drive Conference Brussels, 2007.

Van Mierlo, J., P. Van den Bossche, and G. Maggetto, Models of energy sources for EV and HEV: Fuel cells, batteries, ultracapacitors, flywheels and engine-generators, Journal of Power Sources, Vol. 128, No. 1, 76-89, 2003.

Van Mierlo, J., Simulation software for comparison and design of electric, hybrid and internal combustion vehicles with respect to energy, emissions and performances, Department of Electrical Engineering, Vrije Universiteit Brussel, 2000.

(Received March 31, 2009; accepted July 30, 2009) 